\title{
Expression of $\beta 1$ - and $\beta 2$-adrenergic receptors in the lungs and changes in the levels of corresponding autoantibodies in an aged rat model of heart failure
}

\author{
XIANG-YANG FANG $^{1 *}$, ZHE CHEN $^{1 *}$, GUO-BIN MIAO $^{2}$ and LIN ZHANG ${ }^{3}$ \\ ${ }^{1}$ Department of Internal Medicine, Beijing Chaoyang Hospital, Capital Medical University, \\ Beijing 100020; ${ }^{2}$ Heart Center, Beijing Tsinghua Changgung Hospital, Beijing 102218; ${ }^{3}$ Heart Center, \\ Beijing Chaoyang Hospital, Capital Medical University, Beijing 100020, P.R. China
}

Received December 7, 2015; Accepted October 11, 2016

DOI: $10.3892 / \mathrm{ijmm} .2016 .2786$

\begin{abstract}
ARs) and anti- $\beta 1$-AR autoantibodies play important roles in heart failure. This study was designed to investigate the expression of $\beta 1$ - and $\beta 2$-ARs in the lungs, and their relevance to the corresponding autoantibodies in an aged rat model of heart failure. In addition, we investigated the association between anti- $\beta$-AR autoantibody and soluble Fas (sFas) and soluble Fas ligand (sFasL). Aged male Wistar rats were divided into the sham-operated control group and the heart failure group. At 0 and 9 weeks post-surgery, the protein levels of $\beta 1$ - and $\beta 2$-ARs in the heart and lungs were measured by western blot analysis. The plasma concentrations of autoantibodies, sFas and sFasL were determined by enzymelinked immunosorbent assay (ELISA). The protein levels of pulmonary $\beta 1$ - and $\beta 2$-ARs were decreased in the heart failure group when compared with the control group $(\mathrm{P}<0.01)$. Both the frequencies of the occurrence and the titers of autoantibodies against $\beta 2$-AR increased at 9 weeks post-surgery $(\mathrm{P}<0.01)$. The levels of sFas and sFasL were also elevated, although there was no difference in the levels of sFas and sFasL between the groups, with positive and negative anti- $\beta$-AR autoantibody. These findings suggested that during the development of heart failure, the densities of pulmonary $\beta 1$ - and $\beta 2$-ARs decreased. The levels of anti-ß32-AR autoantibody exhibited similar changes as those of anti- $\beta 1-A R$ autoantibody, and there was no definite association between anti- $\beta$-AR autoantibody and the levels of sFas/sFasL.
\end{abstract}

Correspondence to: Dr Lin Zhang, Heart Center, Beijing Chaoyang Hospital, Capital Medical University, 8 Gongti South Road, Beijing 100020, P.R. China

Email: linzhangteacher@sina.com

*Contributed equally

Key words: $\beta$-adrenergic receptor, autoantibody, heart failure, apoptosis, aged

\section{Introduction}

The $\beta$-adrenergic receptor ( $\beta$-AR) belongs to the family of $\mathrm{G}$ protein-coupled receptors and consists of 3 subtypes: $\beta 1-, \beta 2-$ and $\beta 3-A R$. The different subtypes are associated with different changes during the course of heart failure. the stimulation of $\beta 1$ - and $\beta 2$-AR produces positive chronotropic and inotropic effects, while the activation of $\beta 3$-AR decreases the contractility of the myocardium. In the failing ventricular myocardium, $\beta 1-\mathrm{AR}$ is downregulated, whereas $\beta 2$-AR exhibits little or no change. However, $\beta 3-A R$ is upregulated (1-4). Pulmonary edema is a main complication of heart failure. $\beta$-ARs also exist in the lungs, where the dominant subtype is $\beta 2$-AR (5). There are currently few available articles on the changes in $\beta$-AR levels in the lungs during the course of heart failure. A recent study demonstrated that the $\beta 2-\mathrm{AR}$ mRNA level was significantly decreased in a murine model of heart failure in pulmonary tissues (6). Our previous study demonstrated a decrease in $\beta 3$-AR mRNA and protein in the lungs of an aged rat model during heart failure (3). However, to the best of our knowledge, we have not found any article discussing the changes in the levels of pulmonary $\beta 1$ - and $\beta 2$-ARs during the course of heart failure in aged rats. It is commonly observed that heart failure occurs mainly in aged subjects, and aged individuals have some physiological and pathological characters which differ from those of young individuals (7). Aging should be considered as an important factor when elucidating cardiac disease mechanisms (7).

The pathogenetic role of anti- $\beta 1-A R$ autoantibody has long been researched in experimental models $(8,9)$, and anti- $\beta 1-A R$ autoantibody is closely associated with cardiac sympathetic nervous activity and reduced cardiac function in patients with heart failure (10). Anti- $\beta 1$-AR autoantibody induces the apoptosis of adult rat cardiomyocytes (11). We hypothesized that since $\beta 2$-AR also belongs to $\beta$-ARs (the $G$ protein-coupled receptors characterized by 7 transmembrane domains of 22-28 amino acids and having 3 intracellular and 3 extracellular loops), its corresponding autoantibody would undergo similar changes during the course of heart failure.

Fas, a type I membrane protein, is a member of the tumor necrosis factor (TNF) gene superfamily, which is distributed 
on the cytoplasmic membrane. Fas ligand (FasL), a cell surface molecule also belonging to the tumor necrosis (TNF) family, binds to its receptor Fas, thus activating the caspase system and inducing apoptosis (12). The Fas/FasL system suggests a pathophysiological role of cardiomyocyte apoptosis in patients with worsening heart failure. Circulating apoptotic mediators (sFas and sFasL) have been shown to be significantly higher in patients with chronic heart failure as compared to normal control subjects $(13,14)$. Thus, in this study, we also investigated the association between anti- $\beta$-AR autoantibody and the apoptotic mediators, sFas and sFasL.

Based on these considerations, in this study, we used aged Wistar rats to examine the expression levels of $\beta 1$ - and $\beta 2$-ARs in the lungs and the changes in anti- $\beta 2$-AR autoantibody in a rat model of heart failure. We also investigated apoptotic factors (sFas and $\mathrm{sFasL}$ ) in a rat model of heart failure. The findings of this study suggested that the densities of pulmonary $\beta 1$ - and $\beta 2$-ARs decreased, while the levels of anti- $\beta 2-A R$ autoantibody exhibited changes similar to those of anti- $\beta 1-A R$ autoantibody.

\section{Materials and methods}

Animal model. All the animal experiments were approved by the Institutional Animal Care and Use Committee of Capital Medical University (Beijing, China; 10-A-35). Male Wistar rats (20 months old; body weight, 400-450 g) were housed ( 3 animals/cage) in a room with a controlled temperature $\left(22^{\circ} \mathrm{C}\right)$ and a 12 -h light/12-h dark cycle. The rats were randomly divided into 2 groups as follows: the heart failure group $(n=50)$ and the sham-operated group $(n=30)$. Endotracheal intubation was performed as previously described by Brown et al (15). The rat model of heart failure was established as follows: through a small incision at the second intercostal space, the transverse aorta was isolated. A stenosis of the ascending aorta was induced by a ligation of the aorta (steel wire area/ascending aorta area, 75\%), as previously described (16). The sham-operated group underwent the same surgical procedure, but without the occlusion of the aorta. At $24 \mathrm{~h}$ (0 week) or 9 weeks post-surgery, the animals ( 0 week, sham-operated group, $n=11$; heart failure group, $\mathrm{n}=12$; 9 weeks, sham-operated group, $\mathrm{n}=16$; heart failure group, $n=18$ ) were anesthetized by intraperitoneal injection of urethane $(20 \%, 1 \mathrm{~g} / \mathrm{kg})$ and a cannula connected to a pressure transducer was inserted along the carotid artery into the left ventricle to measure the primary and derived variables, including heart rate (HR), left ventricular end-systolic pressure (LVESP), left ventricular end-diastolic pressure (LVEDP), maximum rate of rise of left ventricular pressure (+dp/dt max) and maximum rate of fall of left ventricular pressure (-dp/dt max). A pressure transducer connected to a polygraph recorder was used to measure the pressure. The left ventricles and lungs were rapidly excised, rinsed in ice-cold isotonic saline, and weighed and frozen in liquid nitrogen. During the course of the experiment, $2 \mathrm{ml}$ of blood sample was obtained from the carotid artery from both groups. The sera were separated. The sera and the tissues were stored at $-80^{\circ} \mathrm{C}$ until further analysis.

Determination of anti- $\beta$-ARs autoantibody concentrations by enzyme-linked immunosorbent assay (ELISA).
Table I. Mortality of aged rats.

\begin{tabular}{lcc}
\hline Time & $\begin{array}{c}\text { Sham-operated } \\
\text { group } \\
(\mathrm{n}=30)\end{array}$ & $\begin{array}{c}\text { Heart failure } \\
\text { group } \\
(\mathrm{n}=50)\end{array}$ \\
\hline 0 week (within 24 h) & $3(10 \%)$ & $4(8 \%)$ \\
1 week (24 h to 7 days) & 0 & $3(6 \%)$ \\
2 weeks & 0 & $2(4 \%)$ \\
3 weeks & 0 & $1(2 \%)$ \\
4 weeks & 0 & $1(2 \%)$ \\
5 weeks & 0 & 0 \\
6 weeks & 0 & $1(2 \%)$ \\
7 weeks & 0 & 0 \\
8 weeks & 0 & $5(6 \%)$ \\
9 weeks & 0 & $20(40 \%)$ \\
Total & $3(10 \%)$ & \\
\hline
\end{tabular}

Two peptides with cysteine at the terminal position, corresponding to the sequence of the second extracellular loop of the rat $\beta 1-A R$ (residues 197-222, H-W-W-R-A-E-S-DE-A-R-R-C-Y-N-D-P-K-C-C-D-F-V-T-N-R-C) and $\beta 2-A R$ (residues 173-198, W-Y-R-A-T-H-K-Q-A-I-D-C-Y-A-K-E-TC-C-D-F-F-T-N-Q-A-C·), were synthesized by the Institute of Laboratory Animal Science, Chinese Academy of Medical Sciences (CAMS) and Peking Union Medical College (PUMC) (Beijing, China), using the solid phase method of Merrifield. The presence of the autoantibodies was detected by ELISA as previously described (8).

Determination of $\beta$-AR protein expression by western blot analysis. Cardiac and pulmonary tissues ( $\mathrm{n}=8$ for each group) were homogenized in ice-cold homogenization buffer separately and then centrifuged at $12,000 \times \mathrm{g} 4^{\circ} \mathrm{C}$. Total protein was isolated from the tissues and the concentration was determined using the Bradford method. The protein sample $(80 \mu \mathrm{g})$ was separated by $10 \%$ sodium dodecyl sulphate-polyacrylamide gel electrophoresis and then transferred onto nitrocellulose membranes. The membranes were blocked for $1 \mathrm{~h}$ at room temperature in TBS-T, containing 5\% non-fat milk and probed with 1:1,000 diluted primary antibodies against glyceraldehyde 3-phosphate dehydrogenase (GAPDH; TA-08; made in USA, subpackaged by ZSGB-BIO, Beijing, China) and $\beta 1-$ and $\beta 2-A R s$ [ $\beta 1-A R$ (V-19): sc-568, $\beta 2-A R(M-20)$ : sc-570; Santa Cruz Biotechnology, Santa Cruz, CA, USA]. Goat antimouse (ZB-2305; made in USA, subpackaged by ZSGB-BIO) or goat anti-rabbit (ZB-2301,made in USA, subpackaged by ZSGB-BIO) antibodies (1:3,000 dilution) were used as secondary antibodies to incubate the blots for $1 \mathrm{~h}$. Bands on the blots were visualized using western blot kit (Promega, Madison, WI, USA) and semi-quantified using a computer image analysis system (Quantity One software v4.62; Bio-Rad, Hercules, CA, USA).

Measurement of serum sFas/sFasL levels. The serum concentrations of sFas and sFasL were measured using commercially available ELISA kits, according to the manufacturer's instruc- 
Table II. Changes in cardiac function.

\begin{tabular}{lccccccc}
\hline Group & $\begin{array}{c}\text { Time } \\
\text { (weeks) }\end{array}$ & $\mathrm{n}$ & $\begin{array}{c}\text { HR } \\
(\mathrm{bpm})\end{array}$ & $\begin{array}{c}\text { LVESP } \\
(\mathrm{mmHg})\end{array}$ & $\begin{array}{c}\text { LVEDP } \\
(\mathrm{mmHg})\end{array}$ & $\begin{array}{c}+\mathrm{dp} / \mathrm{dt} t_{\max } \\
(\mathrm{mmHg} / \mathrm{msec})\end{array}$ & $\begin{array}{c}-\mathrm{dp}^{2} \mathrm{dt}_{\max } \\
(\mathrm{mmHg} / \mathrm{mmec})\end{array}$ \\
\hline Sham & 0 & 11 & $327 \pm 16$ & $127.7 \pm 5.9$ & $1.07 \pm 0.10$ & $9.84 \pm 0.72$ & $-6.41 \pm 0.72$ \\
& 9 & 16 & $325 \pm 13$ & $129.7 \pm 5.8$ & $1.15 \pm 0.14$ & $9.46 \pm 0.54$ & $-6.10 \pm 0.41$ \\
HF & 0 & 12 & $332 \pm 18$ & $131.2 \pm 4.8$ & $1.13 \pm 0.13$ & $9.56 \pm 0.49$ & $-6.00 \pm 0.65$ \\
& 9 & 18 & $291 \pm 16^{\mathrm{a}}$ & $91.7 \pm 7.2^{\mathrm{a}}$ & $10.53 \pm 0.60^{\mathrm{a}}$ & $4.23 \pm 0.07^{\mathrm{a}}$ & $-2.61 \pm 0.25^{\mathrm{a}}$ \\
\hline
\end{tabular}

${ }^{\mathrm{a} P}<0.01$, HF group vs. sham-operated (Sham) group; HR, heart rate; LVESP, left ventricular end-systolic pressure; LVEDP, left ventricular end-diastolic pressure; $+\mathrm{dp} / \mathrm{dt}_{\max }$, maximum rate of rise of left ventricular pressure; - $\mathrm{dp} / \mathrm{dt}_{\max }$, maximum rate of fall of left ventricular pressure.

A

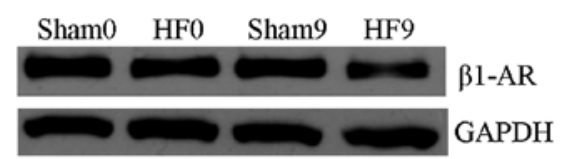

B

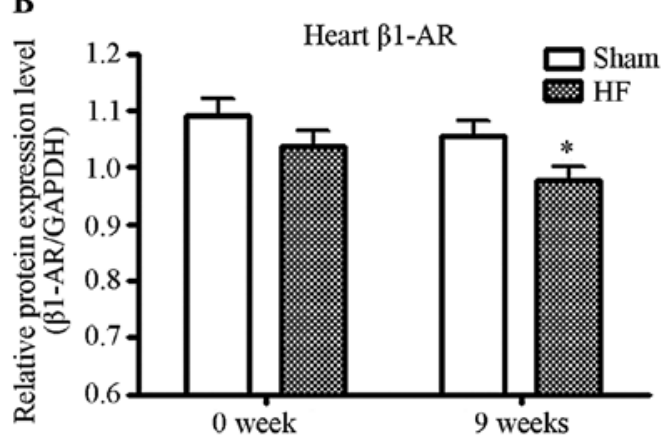

C Sham0 HF0 Sham 9 HF9

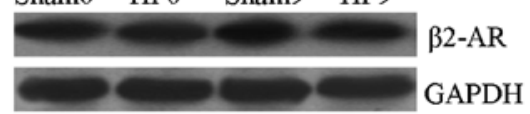

D

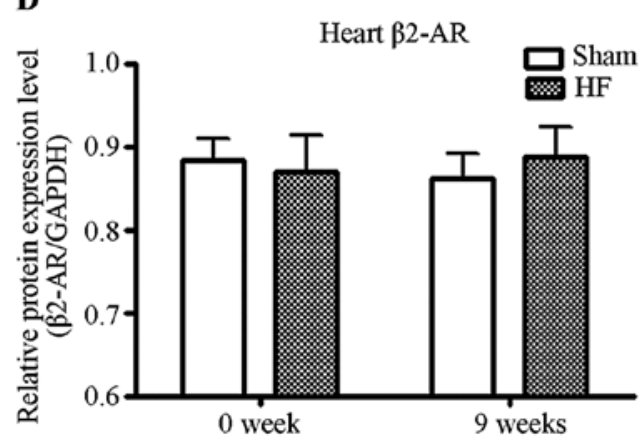

Figure 1. Protein expression of $\beta$-adrenergic receptors ( $\beta 1$ - and $\beta 2$-AR) examined by western blot analysis in the left ventricle. (A) Immunoblot of $\beta 1-A R$ protein and glyceraldehyde 3-phosphate dehydrogenase (GAPDH) in representative animals. Sham0: week 0, sham-operated (sham) group; HF0: week 0, heart failure (HF) group; Sham9: week 9, sham group; HF9: week 9, HF group. (B) Bar plot represent the data from myocardial tissues of all animals in each group. $\beta 1$-AR protein revealed a decrease with the deterioration of heart function. (" $\mathrm{P}<0.05$ vs. sham group, 9 weeks post-surgery). (C) Immunoblot of $\beta 2$-AR protein in representative animals. (D) Bar plot showed the data from myocardial tissues of all animals in each group. The density of $\beta 2$-AR protein didn't show any significant change in heart failure group compared with the control $(\mathrm{P}>0.05)$.

tions. The kits were obtained from Shanghai Senxiong Biotech Industry Co., Ltd. (Shanghai, China). Each group consisted of 8 rats.

Data analysis. Data are expressed as the means $\pm \mathrm{SD}$. The mean of antibody titers is represented by geometric means. A statistical comparison of group means was performed using the Student's t-test. A statistical comparison of the positive ratios of autoantibodies was performed using the Chi-square test. Data analysis was performed using SPSS 13.0 software (SPSS, Inc., Chicago, IL, USA) on a personal computer. A value of $\mathrm{P}<0.05$ was considered to indicate a statistically significant difference, and a value of $\mathrm{P}<0.01$ was considered to indicate a highly statistically significant difference.

\section{Results}

Mortality rate of aged rats. The mortality rate in the heart failure group was significantly higher than that in the sham- operated group ( $\mathrm{P}<0.01,40$ vs. 10\%) during the post-operative period (0-9 weeks). The major causes of death were overanesthesia in the sham-operated group and heart failure in the heart failure group (Table I).

Changes in cardiac function. The changes in cardiac function are presented in Table II. At 9 weeks post-surgery, the cardiac function parameters, LVESP and the maximum rate of rise or fall of left ventricular pressure absolute values, were significantly decreased in the rats in the heart failure group as compared to the control animals $(\mathrm{P}<0.01)$. LVEDP was significantly increased $(\mathrm{P}<0.01)$ in the heart failure group, which indicated the occurrence of heart failure.

The protein levels of $\beta 1-$ and $\beta 2-A R s$. The protein levels of $\beta 1$ - and $\beta 2$-ARs in the left ventricle of the rats from the control and heart failure groups were quantified by western blot analysis. As shown in Fig. 1, the density of $\beta 1-A R$ protein in the heart failure group decreased significantly as compared 

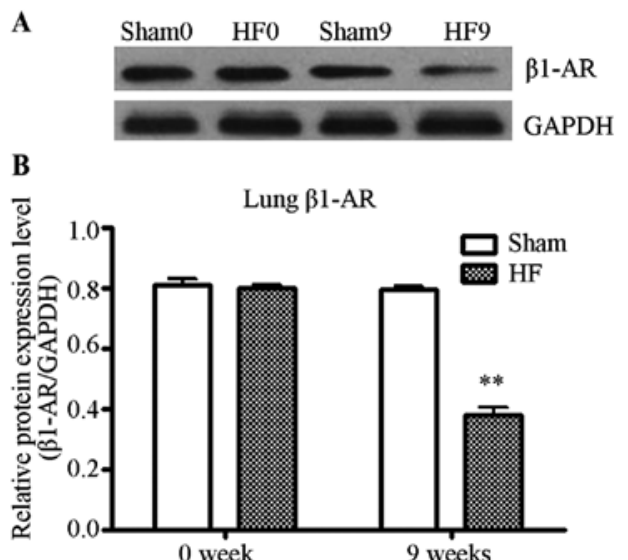

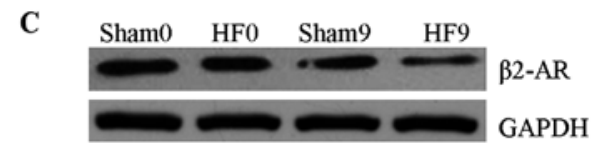

D

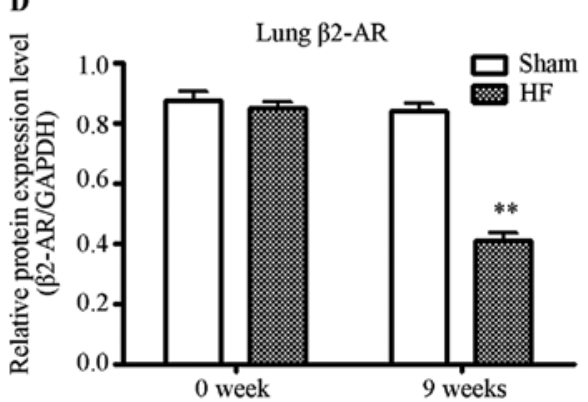

Figure 2. Protein expression of $\beta$-adrenergic receptors ( $\beta 1$ - and $\beta 2$-AR) examined by western blot analysis in lungs. (A) Immunoblot of $\beta 1-A R$ protein in representative animals. Sham0: week 0, sham-operated (sham) group; HF0: week 0, heart failure (HF) group; Sham9: week 9, sham group; HF9: week 9, HF group. (B) Bar plot represents the data from pulmonary tissues of all animals in each group. $\beta 1-A R$ protein revealed a decrease with the deterioration of heart function.

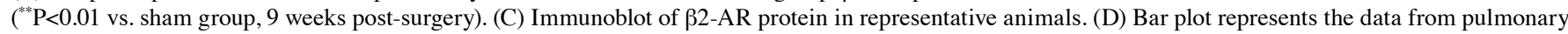
tissues of all animals in each group. $\beta 2$-AR protein revealed a decrease with the deterioration of heart function ( ${ }^{* *} \mathrm{P}<0.01$ vs. sham group, 9 weeks post-surgery).
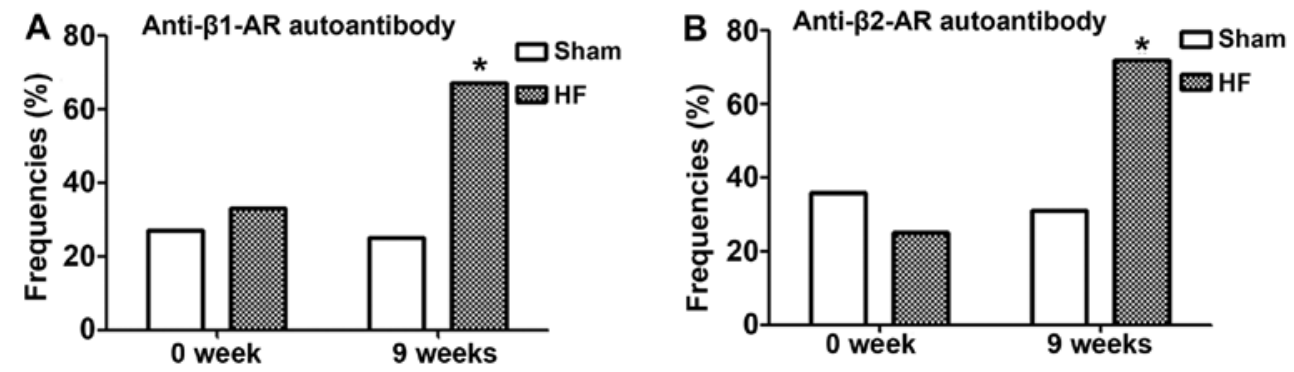

Figure 3. Changes in the frequencies of (A) anti- $\beta$-adrenergic receptor ( $\beta 1$-AR) autoantibody and (B) anti- $\beta 2$-AR autoantibody. Frequencies of anti- $\beta 1$ - and - $\beta 2$ ARs were significantly higher in the heart failure (HF) group than in the sham-operated (sham) group with the deterioration of heart function ("P $<0.05$ vs. sham group, 9 weeks post-surgery).
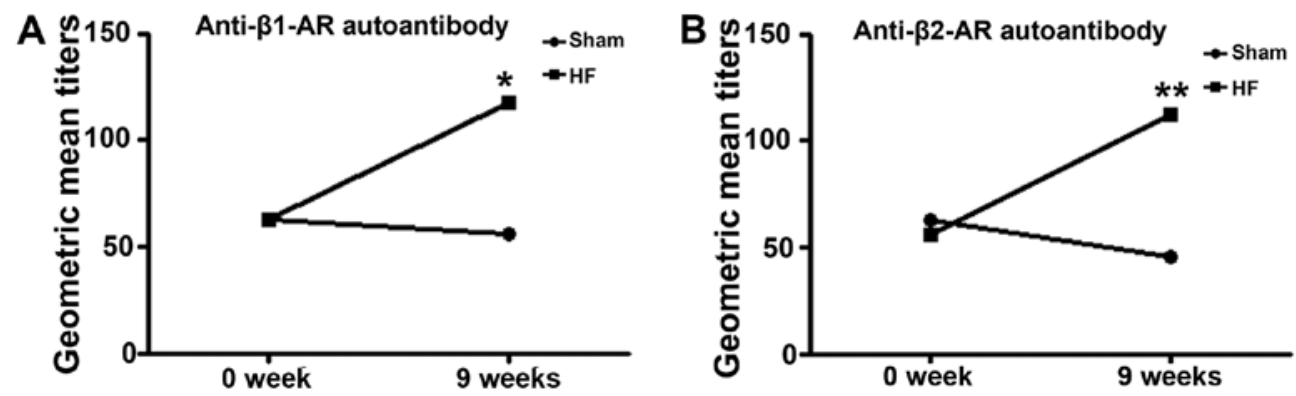

Figure 4. Changes in the titers of (A) anti- $\beta$-adrenergic receptor ( $\beta 1-\mathrm{AR})$ autoantibody and (B) anti- $\beta 2$-AR autoantibody. Geometric mean titers of anti$\beta 1$ - and - $\beta 2$-ARs were significantly higher in the hear failure (HF) group than in the sham-opreated (sham) group with the deterioration of heart function (" $\mathrm{P}<0.05$ and ${ }^{* *} \mathrm{P}<0.01$ vs. sham group, 9 weeks post-surgery).

to the control $(\mathrm{P}<0.01)$. The density of $\beta 2-\mathrm{AR}$ protein however, did not exhibit any significant change in the heart failure group, as compared to the control $(\mathrm{P}>0.05)$. The protein levels of $\beta 1$ - and $\beta 2$-ARs in the lungs of rats from the control and heart failure groups were quantified by western blot analysis. As shown in Fig. 2, at 9 weeks post-surgery, the density of $\beta 1$ - and $\beta 2-A R$ protein in the heart failure group decreased significantly as compared to the control $(\mathrm{P}<0.01)$.
Changes in the frequencies of the occurrence and titres of autoantibodies. At 9 weeks post-surgery, when cardiac function exhibited significant changes, the positive ratios of the anti- $\beta 1$ - and - $\beta 2-\mathrm{AR}$ autoantibodies were increased from 25 and 31.3 to 66.7 and $72.2 \%$, respectively $(\mathrm{P}<0.05 ;$ Fig. 3 ). The anti- $\beta 1-$ and $-\beta 2-A R$ antibody titers were increased from $1:(39.8 \pm 1.6)$ and $1:(45.7 \pm 1.8)$ to $1:(117.5 \pm 1.8)(\mathrm{P}<0.05)$ and 1:(112.2 \pm 2.0$)(\mathrm{P}<0.05)$, respectively (Fig. 4). 

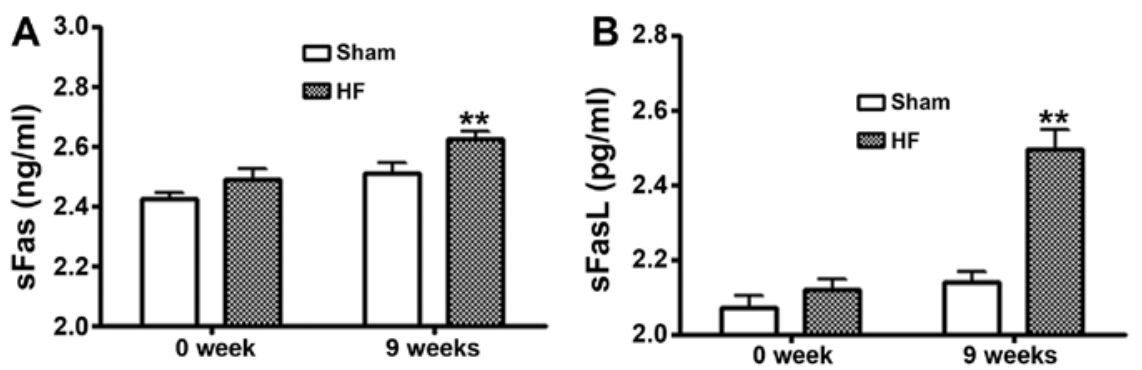

Figure 5. Serum levels of (A) soluble Fas (sFas) and (B) soluble Fas ligand (sFasL). The levels of sFas/sFasL in the heart failure (HF) group increased significantly compared with the control [sham-operated (sham) group] ( ${ }^{* *} \mathrm{P}<0.01$ vs. sham group, 9 weeks post-surgery).

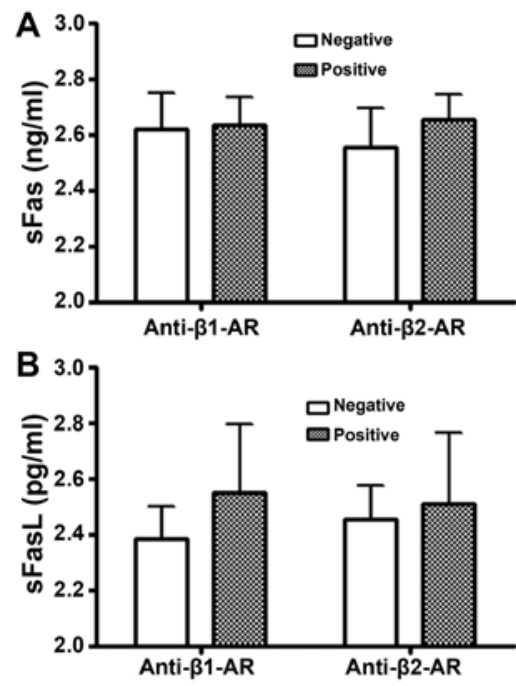

Figure 6. Levels of soluble Fas (sFas) and Fas ligand (sFasL) in heart failure group with positive or negative autoantibody. (A) There was no difference in the levels of sFas or sFasL between the groups with positive and negative anti- $\beta 1-A R$ autoantibody. (B) There was no difference in the levels of sFas or sFasL between the groups with positive and negative anti- $\beta$ adrenergic receptor $(\beta-\mathrm{AR})$ autoantibody.

Serum levels of $s F a s / s F a s L$. The levels of $s F a s / s F a s L$ in serum from the rats in the control and heart failure groups were measured by ELISA. As shown in Fig. 5, at 9 weeks postsurgery the levels of sFas/sFasL in the heart failure group were significantly increased as compared to the control $(\mathrm{P}<0.01)$.

Levels of sFas/sFasL at 9 weeks post-surgery in the heart failure group. There were 18 animals at 9 weeks post-surgery in the heart failure group. We defined the 12 animals with positive anti- $\beta 1-A R$ autoantibody as the group with positive anti- $\beta 1-A R$ autoantibody, and the 6 animals with negative anti- $\beta 1$-AR autoantibody as the group with negative anti- $\beta 1-A R$ autoantibody. We defined the 13 animals with positive anti- $\beta 2$-AR autoantibody as the group with positive anti- $\beta 2$-AR autoantibody, and the 5 animals with negative anti- $\beta 2-\mathrm{AR}$ autoantibody as the group with negative anti- $\beta 2-\mathrm{AR}$ autoantibody. There were no differences observed in the levels of sFas or sFasL between the groups with positive and negative anti- $\beta 1-\mathrm{AR}$ autoantibody. In addition, there were no differences observed in the levels of sFas or sFasL between the groups with positive and negative anti-ß2-AR autoantibody (Fig. 6).

\section{Discussion}

The data from the present study provided three important observations: i) a decrease in the pulmonary $\beta 1$ - and $\beta 2$-AR protein levels during the development of heart failure; ii) at 9 weeks post-surgery, both the frequency of the occurrence and the titres of anti- $\beta 2-A R$ autoantibody were significantly increased as compared to those of the control; and iii) at 9 weeks postsurgery, the levels of sFas/sFasL in the heart failure group decreased significantly as compared to those of the control. From these results, we can draw some important conclusions.

Changes in the densities of pulmonary $\beta 1$ - and $\beta 2$-ARs the rat model of heart failure. Studies carried out on adult rats have demonstrated that in the failing ventricular myocardium, $\beta 1$-AR is downregulated, whereas $\beta 2$-AR exhibits little or no change $(1,2)$. Similar results were observed in aged rats. Pulmonary edema is the main threatening complication of heart failure. Since $\beta$-ARs also exist in the lungs, we wished to determine whether pulmonary $\beta 1$ - and $\beta 2$-ARs experience any changes in a rat model of heart failure. Fewer studies have related the changes in the levels of pulmonary $\beta$-ARs during the course of heart failure. In 1999, Borst et al studied the changes in the total AR density in a rat model of heart failure and concluded that the density was significantly decreased (17). However, due to the presence of 3 subtypes of $\beta$-ARs, studies on the changes of different subtypes are mandatory. Our study demonstrated that in an aged rat model of heart failure, the levels of both pulmonary $\beta 1$ - and $\beta 2$-ARs were significantly decreased, and the changes in these levels differed from those in the heart. The respiratory system is characterized by the prevalence of $\beta 2$-AR. $\beta 2$-AR plays a key role in both the regulation of airway smooth muscle tone and lung fluid clearance, which influences gas diffusion $(18,19)$. $\beta 1$-AR is also present in the lungs, and accounts for 10 and $30 \%$ of the ARs on submucosal glands and alveolar walls, respectively (20). Some studies have indciated that both $\beta 1$ - and $\beta 2$-AR agonists increase alveolar fluid clearance in experimental models $(21,22)$. The decrease in the levels of pulmonary $\beta 1$ - and $\beta 2$-ARs during the course of heart failure may increase the airway smooth muscle tone and reduce lung fluid clearance. This change may aggravate pulmonary edema to a certain extent.

Changes in the levels of anti- $\beta 2-A R$ autoantibody during the course of heart failure. We chose to use aged 20-month-old Wistar rats as experiment animals and established a model of 
heart failure by aortic binding. We found that both the frequency of the occurrence and the titre of anti- $\beta 1-A R$ autoantibody were significantly increased as compared to the control. More importantly, it was observed that anti- $\beta 2-\mathrm{AR}$ autoantibody exhibited a similar change to that of anti- $\beta 1-A R$ autoantibody. Thus, it was opined that anti- $\beta 1-\mathrm{AR}$ autoantibody was closely associated with cardiac sympathetic nervous activity and cardiac event in patients with chronic heart failure $(10,23,24)$. Heart failure can trigger anti- $\beta 1-A R$ autoantibody and conversely, anti- $\beta 1-A R$ autoantibody can aggravate heart failure. Carvedilol $(\beta-A R$ blocker) has been shown to be effective in improving cardiac dysfunction and reversing remodeling in patients positive for anti- $\beta$-AR autoantibody (25). Stavrakis et al (26) demonstrated that the co-existence of anti- $\beta 2-A R$ autoantibody partially suppressed the effect of the anti- $\beta 1-A R$ autoantibody, although the study was carried out on patients with cardiomyopathy and not on patients with heart failure. Our study demonstrated that heart failure can also trigger anti- $\beta 2$-AR autoantibody. Since anti- $\beta 1-A R$ autoantibody can aggravate heart failure and the co-existence of anti- $\beta 2-A R$ autoantibody can partially suppress the effect of the anti- $\beta 1-A R$ autoantibody, we opined that anti$\beta 2-\mathrm{AR}$ autoantibody can alleviate heart failure to a certain extent during the course of heart failure. The rate of autoantibodies against two types of $\beta$-ARs was $24.6 \%$, which indicated a multiplicity of autoimmune response in heart failure.

Changes exhibited by $\beta$-ARs and their corresponding autoantibodies during the development of heart failure. Few studies have examined the changes in $\beta$-ARs and the changes in autoantibodies simultaneously $(3,27)$. In this study, we investigated $\beta$-ARs and autoantibodies simultaneously and found that, although the two types of $\beta$-ARs exhibited different changes during the development of heart failure, their corresponding autoantibodies exhibited similar changes. Genetic and pharmacological approaches have demonstrated that the $\beta 1-A R$ constitutes approximately $70-80 \%$ of the cardiac $\beta$-AR complement and plays a predominant role in mediating cardiac inotropic and chronotropic responses to catecholamines (28). In the failing ventricular myocardium and lungs, $\beta 1-\mathrm{AR}$ is downregulated. Therefore, the change in the levels of anti- $\beta 1-A R$ autoantibody was found to be related with the change in the levels of $\beta 1-A R$ in the heart and lungs. $\beta 2-A R$ is the main $\beta$-AR subtype in the lungs (6). In the failing ventricular myocardium, the $\beta 2$-AR protein level was unaltered. Pulmonary $\beta$-receptor density was significantly decreased in a rat model of heart failure (29). Thus, the change in anti- $\beta 2-A R$ autoantibody was mainly associated with the changes in $\beta 2-A R$ in the lungs. Since it was established that the co-existence of anti- $\beta 2$-AR autoantibody partially suppressed the effect of anti- $\beta 1-A R$ autoantibody and affected the constriction of the heart, we speculated that anti- $\beta 2-A R$ autoantibody may act on $\beta 2-A R$ in the lungs and affect the regulation of airway smooth muscle tone and lung fluid clearance. Thus, anti- $\beta 2-A R$ autoantibody may affect the course of heart failure, not only through the heart, but also through the lungs. We only proved the existence of anti- $\beta 2-\mathrm{AR}$ autoantibody in a model of heart failure; further studies are required to investigate anti- $\beta 2-\mathrm{AR}$ autoantibody in more detail.

Association between anti- $\beta$-AR autoantibody and the levels of $s F a s / s F a s L$ during the course of heart failure. With the increase in the frequencies and titres of autoantibodies, the sFas and sFasL levels were also elevated. These exert differential effects on the course of apoptosis. Human sFasL induces apoptosis in vitro and in vivo (30), but sFas inhibits the apoptosis of muscle cells in cell culture (31), and improves the survival of animals with heart failure (32). Norepinephrine stimulates apoptosis via $\beta 1-A R$ and inhibits apoptosis via $\beta 2$-AR. $\beta 1$-AR plays a predominant role in the adult rat cardiac myocyte system, and the net effect of norepinephrine results in an increase in the frequency of apoptosis (33). Anti- $\beta 1-A R$ autoantibody induces the apoptosis of adult rat cardiomyocytes via the protein kinase A cascade (11) and mediates dilated cardiomyopathy agonistically by inducing cardiomyocyte apoptosis (34). Although anti- $\beta 1-A R$ autoantibody induces apoptosis, we did not determine any difference in sFas or sFasL between the groups with positive and negative anti- $\beta 1-A R$ autoantibody. We were not able to find any difference in sFas or sFasL between the groups with positive and negative anti- $\beta 2-A R$ autoantibodies.

In conclusion, the findings of our study suggested that during the development of heart failure, the densities of pulmonary $\beta 1$ - and $\beta 2$-ARs decreased and the changes were different from those occurring in the heart. The levels of anti- $\beta 2-A R$ autoantibody exhibited similar changes to those of anti- $\beta 1-A R$ autoantibody during the course of heart failure. When the frequencies and titres of autoantibodies increased, the levels of sFas and sFasL were also elevated; however, there was no definite association between anti- $\beta$-AR autoantibody and the levels of sFas/sFasL.

\section{Acknowledgements}

The authors of this study acknowledge Ms. Xiu-Lan Liu, Ms. Jing Chang and Ms. Ling-Qiao Lu for their contributions to the data collection. There has been no financial assistance with this project.

\section{References}

1. Bristow MR, Ginsburg R, Umans V, Fowler M, Minobe W, Rasmussen R, Zera P, Menlove R, Shah P and Jamieson S: Beta 1- and beta 2-adrenergic-receptor subpopulations in nonfailing and failing human ventricular myocardium: coupling of both receptor subtypes to muscle contraction and selective beta 1-receptor down-regulation in heart failure. Circ Res 59: 297-309, 1986.

2. Engelhardt S, Böhm M, Erdmann E and Lohse MJ: Analysis of beta-adrenergic receptor mRNA levels in human ventricular biopsy specimens by quantitative polymerase chain reactions: progressive reduction of beta 1-adrenergic receptor mRNA in heart failure. J Am Coll Cardiol 27: 146-154, 1996.

3. Miao G, Chen Z, Fang X, Liu M, Hao G, An H, Zhang Z, Lu L, Zhang J and Zhang L: Relationship between the autoantibody and expression of $\beta 3$-adrenoceptor in lung and heart. PLoS One 8: e68747, 2013.

4. Grossini E, Surico D, Mary DA, Molinari C, Surico N and Vacca G: In anesthetized pigs human chorionic gonadotropin increases myocardial perfusion and function through a $\beta$-adrenergic-related pathway and nitric oxide. J Appl Physiol (1985) 115(4): 422-35, 2013.

5. Mak JC, Nishikawa M, Haddad EB, Kwon OJ, Hirst SJ, Twort CH and Barnes PJ: Localisation and expression of beta-adrenoceptor subtype mRNAs in human lung. Eur J Pharmacol 302: 215-221, 1996.

6. Rinaldi B,Capuano A, GrittiG,Donniacuo M,Scotto Di Vettimo A, Sodano L, Rafaniello C, Rossi F and Matera MG: Effects of chronic administration of $\beta$-blockers on airway responsiveness in a murine model of heart failure. Pulm Pharmacol Ther 28: 109-113, 2014. 
7. Horn MA, Graham HK, Richards MA, Clarke JD, Greensmith DJ, Briston SJ, Hall MC, Dibb KM and Trafford AW: Age-related divergent remodeling of the cardiac extracellular matrix in heart failure: collagen accumulation in the young and loss in the aged. J Mol Cell Cardiol 53: 82-90, 2012.

8. Iwata M, Yoshikawa T, Baba A, Anzai T, Nakamura I, Wainai Y, Takahashi T and Ogawa S: Autoimmunity against the second extracellular loop of beta(1)-adrenergic receptors induces beta-adrenergic receptor desensitization and myocardial hypertrophy in vivo. Circ Res 88: 578-586, 2001.

9. Jahns R, Boivin V, Hein L, Triebel S, Angermann CE, Ertl G and Lohse MJ: Direct evidence for a beta 1-adrenergic receptor-directed autoimmune attack as a cause of idiopathic dilated cardiomyopathy. J Clin Invest 113: 1419-1429, 2004.

10. Aso S, Yazaki Y, Kasai H, Takahashi M, Yoshio T, Yamamoto K and Ikeda U: Anti-beta 1-adrenoreceptor autoantibodies and myocardial sympathetic nerve activity in chronic heart failure. Int J Cardiol 131: 240-245, 2009.

11. Staudt Y, Mobini R, Fu M, Felix SB, Kühn JP and Staudt A: Beta1-adrenoceptor antibodies induce apoptosis in adult isolated cardiomyocytes. Eur J Pharmacol 466: 1-6, 2003.

12. Feng QZ, Zhao YS and Abdelwahid E: The role of Fas in the progression of ischemic heart failure: prohypertrophy or proapoptosis. Coron Artery Dis 19: 527-534, 2008.

13. Adamopoulos S, Parissis J, Karatzas D, Kroupis C Georgiadis M, Karavolias G, Paraskevaidis J, Koniavitou K, Coats AJ and Kremastinos DT: Physical training modulates proinflammatory cytokines and the soluble Fas/soluble Fas ligand system in patients with chronic heart failure. J Am Coll Cardiol 39: 653-663, 2002.

14. Kinugawa T, Kato M, Yamamoto K, Hisatome I and Nohara R: Proinflammatory cytokine activation is linked to apoptotic mediator, soluble Fas level in patients with chronic heart failure. Int Heart J 53: 182-186, 2012.

15. Brown RH, Walters DM, Greenberg RS and Mitzner W: A method of endotracheal intubation and pulmonary functional assessment for repeated studies in mice. J Appl Physiol (1985) 87: 2362-2365, 1999.

16. Chen Z, Miao G, Liu M, Hao G, Liu Y, Fang X, Zhang Z, Lu L, Zhang J and Zhang L: Age-related up-regulation of beta3-adrenergic receptor in heart-failure rats. J Recept Signal Transduct Res 30: 227-233, 2010.

17. Borst MM, Beuthien W, Schwencke C, LaRosée P, Marquetant R, Haass M, Kübler W and Strasser RH: Desensitization of the pulmonary adenylyl cyclase system: a cause of airway hyperresponsiveness in congestive heart failure? J Am Coll Cardiol 34: 848-856, 1999.

18. Carstairs JR, Nimmo AJ and Barnes PJ: Autoradiographic visualization of beta-adrenoceptor subtypes in human lung. Am Rev Respir Dis 132: 541-547, 1985.

19. Agostoni P, Contini M, Cattadori G, Apostolo A, Sciomer S, Bussotti M, Palermo P and Fiorentini C: Lung function with carvedilol and bisoprolol in chronic heart failure: is beta selectivity relevant? Eur J Heart Fail 9: 827-833, 2007.

20. Ruffin RE, McIntyre EL, Latimer KM, Ward HE, Crockett AJ and Alpers JH: Assessment of beta-adrenoceptor antagonists in asthmatic patients. Br J Clin Pharmacol 13 (Suppl 2): 325S-335S, 1982.
21. Sakuma T, Tuchihara C, Ishigaki M, Osanai K, Nambu Y, Toga H, Takahashi K, Ohya N, Kurihara T and Matthay MA: Denopamine, a beta(1)-adrenergic agonist, increases alveolar fluid clearance in ex vivo rat and guinea pig lungs. J Appl Physiol (1985) 90: 10-6, 2001.

22. Lasnier JM, Wangensteen OD, Schmitz LS, Gross CR, Ingbar DH: Terbutaline stimulates alveolar fluid resorption in hyperoxic lung injury. J Appl Physiol (1985) 81(4): 1723-9, 1996.

23. Liu J, Wang Y, Chen M, Zhao W, Wang X, Wang H, Zhang Z, Zhang J, Xu L, Chen J, et al: The correlation between peripartum cardiomyopathy and autoantibodies against cardiovascular receptors. PLoS One 9: e86770, 2014.

24. Yoshikawa T, Baba A and Nagatomo Y: Autoimmune mechanisms underlying dilated cardiomyopathy. Circ J 73: 602-7, 2009.

25. Nagatomo Y, Yoshikawa T, Okamoto H, Kitabatake A and Hori M: Japanese Chronic Heart Failure Study Investigators: Presence of autoantibody directed against $\beta 1$-adrenergic receptors is associated with amelioration of cardiac function in response to carvedilol: Japanese chronic heart failure (J-CHF) study. J Card Fail 21: 198-207, 2015.

26. Stavrakis S, Kem DC, Patterson E, Lozano P, Huang S, Szabo B, Cunningham MW, Lazzara R and Yu X: Opposing cardiac effects of autoantibody activation of $\beta$-adrenergic and M2 muscarinic receptors in cardiac-related diseases. Int J Cardiol 148: 331-336, 2011.

27. Sterin-Borda L, Gorelik G, Postan M, Gonzalez Cappa S and Borda E: Alterations in cardiac beta-adrenergic receptors in chagasic mice and their association with circulating beta-adrenoceptor-related autoantibodies. Cardiovasc Res 41: 116-125, 1999.

28. Lohse MJ, Engelhardt S and Eschenhagen T: What is the role of beta-adrenergic signaling in heart failure? Circ Res 93: 896-906, 2003.

29. Liu HR, Zhao RR, Jiao XY, Wang YY and Fu M: Relationship of myocardial remodeling to the genesis of serum autoantibodies to cardiac beta(1)-adrenoceptors and muscarinic type 2 acetylcholine receptors in rats. J Am Coll Cardiol 39: 1866-1873, 2002.

30. Tanaka M, Suda T, Yatomi T, Nakamura N and Nagata S: Lethal effect of recombinant human Fas ligand in mice pretreated with Propionibacterium acnes. J Immunol 158: 2303-2309, 1997.

31. Vasudevan SS, Lopes NH, Seshiah PN, Wang T, Marsh CB, Kereiakes DJ, Dong C and Goldschmidt-Clermont PJ: Mac-1 and Fas activities are concurrently required for execution of smooth muscle cell death by M-CSF-stimulated macrophages. Cardiovasc Res 59: 723-733, 2003.

32. Li Y, Takemura G, Kosai K, Takahashi T, Okada H, Miyata S, Yuge K, Nagano S, Esaki M, Khai NC, et al: Critical roles for the Fas/Fas ligand system in postinfarction ventricular remodeling and heart failure. Circ Res 95: 627-636, 2004.

33. Communal C, Colucci WS and Singh K: p38 mitogen-activated protein kinase pathway protects adult rat ventricular myocytes against beta -adrenergic receptor-stimulated apoptosis. Evidence for Gi-dependent activation. J Biol Chem 275: 19395-19400, 2000.

34. Jane-wit D, Altuntas CZ, Johnson JM, Yong S, Wickley PJ, Clark P, Wang Q, Popović ZB, Penn MS, Damron DS, et al: Beta 1-adrenergic receptor autoantibodies mediate dilated cardiomyopathy by agonistically inducing cardiomyocyte apoptosis. Circulation 116: 399-410, 2007. 